\title{
Reservoir and routes of transmission of Enterobacter sakazakii (Cronobacter spp.) in a milk powder-producing plant
}

\author{
C. Jacobs, ${ }^{*}$ P. Braun, $†$ and P. Hammer*1 \\ *Max Rubner-Institute, Federal Research Institute of Nutrition and Food, Department of Safety and Quality of Milk and Fish Products, \\ Hermann-Weigmann Straße 1, D-24103 Kiel, Germany \\ †Institute of Food Hygiene of the Faculty of Veterinary Medicine of the University of Leipzig, An den Tierkliniken 1, D-04103 Leipzig, Germany
}

\section{ABSTRACT}

Several outbreaks of Cronobacter spp. (Enterobacter sakazakii) have been described as food-borne illness in neonates and infants. Powdered infant formula has been identified as a source of infection, especially in hospital nurseries, where a bulk of formula nutrient is prepared for the whole day and instructions for preparation are not always followed correctly. Neonates who are underweight or immunosuppressed are especially at risk for an E. sakazakii infection. Considering that milk powder is the main ingredient of powdered infant formula, we analyzed the incidence and distribution of E. sakazakii in a milk powder-producing plant. We looked specifically at the spray-drying towers and roller dryers. Selected isolates from samples taken from the environment and final product were typed by pulsedfield gel electrophoresis to investigate the epidemiology of the organism within the production area of the plant. Seven pulsed-field gel electrophoresis types were detected in the spray-drying area, which presumably entered the plant through an aperture for process air and an improperly controlled roller shutter. Furthermore, textile filters for exhaust air of both the spraydrying towers were identified as internal reservoirs of the pathogen. For economic reasons, powder from the textile filters is reintroduced into the product flow; this can contaminate the final product. For the production of milk powder to be used as an ingredient of powdered infant formula, it was suggested to terminate the process of reintroducing the filtered powder into the product flow. A second transmission route was identified in the roller dryer section of the factory. It could be shown that contaminated milk concentrate could pass the process unheated, thus leading to a contamination of the product with E. sakazakii.

Key words: Cronobacter spp., milk powder, reservoir, transmission

Received February 28, 2011.

Accepted April 10, 2011.

${ }^{1}$ Corresponding author: philipp.hammer@mri.bund.de

\section{INTRODUCTION}

Cronobacter spp. (Enterobacter sakazakii) is an opportunistic pathogen that is occasionally associated with food-borne illnesses in premature newborns and infants. Taxonomic studies conducted by Iversen et al. (2008) led to a reclassification of E. sakazakii into a new genus, Cronobacter, which presently contains 6 different species. As the results presented here were obtained before this reclassification, the term E. sakazakii will be used for the purpose of this report. The natural habitat of E. sakazakii is still unknown (Muytjens and Kollee, 1990; Kandhai et al., 2004; Drudy et al., 2006; Grimont and Grimont, 2006). Possible reservoirs, including the gastrointestinal tract of flies (Hamilton et al., 2003) and mineral water springs (Mosso et al., 1994), are discussed. In addition to infant formula, the pathogen has been isolated from a broad range of foods such as salads and vegetables (Kim and Beuchat, 2005), ultra high temperature-processed milk (Hamilton et al., 2003), and minced meat (Leclercq et al., 2002). The estimated infection dose is lower than $3 \mathrm{cfu} / 100 \mathrm{~g}$ (FAO/WHO, 2004). Infected neonates suffer from meningitis, septicemia, and necrotizing enterocolitis (Arseni et al., 1987; Biering et al., 1989; van Acker et al., 2001; Block et al., 2002; Himelright et al., 2002; Stoll et al., 2004; Coignard et al., 2006). A high mortality rate and severe sequelae, such as tetraplegia or a developmental disorder upon recovery, are associated with the illness (Muytjens et al., 1983; Willis and Robinson, 1988; Hawkins et al., 1991; Lai, 2001; van Acker et al., 2001; Nazarowec-White et al., 2003; Lehner and Stephan, 2004). In several outbreaks, powdered infant formula has been identified as the source of E. sakazakii that led to the infection (Nazarowec-White and Farber, 1999; Block et al., 2002; Himelright et al., 2002; Coignard et al., 2006). Usually, milk powder is the main ingredient of powdered infant formula. Enterobacter sakazakii has already been detected in milk powder and milk proteinproducing facilities (Mullane et al., 2007, 2008; Proudy et al., 2008; Hein et al., 2009; Craven et al., 2010). Craven et al. (2010) showed that more isolations of the 
pathogen occurred in the non-processing (49\%) than in the processing areas (29\%). Between 4 and 7 clones could be detected in the powder production areas at the 5 factories investigated, whereas the most prevalent and persistent clones were isolated from external roofs above spray driers, in air-treatment areas, and in areas with high foot traffic. Proudy et al. (2008) recovered the majority of isolates (78\%) from the processing environment (such as the surfaces surrounding the dryer, blenders, storage silo areas, or floors of the packaging areas), $12 \%$ from the ingredients, and $10 \%$ from the final products. Seventy percent of the isolates had the same fingerprint. Contamination pathways studied by Mullane et al. (2008) showed that air filters could be a port of entry into the product.

In our study, the incidence and distribution of $E$. sakazakii in a powdered milk-producing plant, where a contamination had already been identified, was investigated. The objective was to identify contamination pathways and, thus, gain an understanding about how to minimize or eradicate product contamination. During a period of $3 \mathrm{yr}$ (2005-2007), E. sakazakii was isolated in the spray-drying and roller-drying areas of the plant. In a subsequent period (2008-2009), investigations were focused on the roller-drying area only. Selected isolates, collected from the environment and final product samples were typed by pulsed-field gel electrophoresis (PFGE) to investigate the epidemiology of this organism within the production area of the plant.

\section{MATERIALS AND METHODS}

\section{Spray-Drying Process}

The subject of this study was a plant with 2 spraydrying towers, which predominantly produced skim milk powder at a rate of $2.5 \mathrm{t} / \mathrm{h}$ from each tower. In addition, whole milk powder was produced with roller dryers (see below, Roller-Drying Process). These dryers were located in different buildings.

After the raw milk got delivered, it was separated into cream and skim milk and pasteurized at 72 to $74^{\circ} \mathrm{C}$ for 15 to $20 \mathrm{~s}$. Afterward, the skim milk was concentrated to $50 \% \mathrm{DM}$ in multiple steps at 74 to $120^{\circ} \mathrm{C}$, with holding times of a few seconds up to $5 \mathrm{~min}$. An additional heat treatment of the concentrate for $30 \mathrm{~s}$ at 70 to $72^{\circ} \mathrm{C}$ preceded the spray-drying process with air (preheated to $210^{\circ} \mathrm{C}$ ). The milk powder was then collected and cooled by air in a fluidized bed dryer and stored in silos before being packed and shipped. To extract the rest of powder from the air-drying stream, cyclones and filters with a large bundle of textile hoses were used. The milk powder collected by the filters could be reintroduced into the powder flow in the fluidized bed dryer, or could be packed separately. For the ventilation of the spraydrying area, especially for the drying and transporting of the milk powder, approximately $100,000 \mathrm{~m}^{3}$ of air were needed per hour. This air was obtained within the building, and was supplied by a $15 \mathrm{~m}^{2}$ aperture. All of the air that was needed for the different processing steps was filtered by an intake system. Filters were of high-efficiency particulate air (HEPA) 10 quality, withholding $99.99 \%$ of particles of $0.3 \mu \mathrm{m}$ and larger. The resulting air circulation is illustrated in Figure 1.

\section{Roller-Drying Process}

For roller drying, the same concentrates were used as for spray drying, but were also enriched with milk fat to obtain powder with a $26 \%$ fat content. In total, 4 roller dryers of identical construction were used. The heating conditions were 150 to $160^{\circ} \mathrm{C}$ for $1.5 \mathrm{~s}$, as calculated from the speed of rotation and the diameter of the drying rolls. These were heated from the inside by steam. The production capacity of each dryer was 175 $\mathrm{kg} / \mathrm{h}$, which was unified to a common stream of dried product.

\section{Samples}

During a period of 3 yr (2005-2007), environmental and final product samples in the spray-drying area and the roller-drying area were collected. All of the environmental samples were collected by swabbing areas of interest. Attempts to use vacuum cleaners, as proposed by Reich et al. (2010), did not prove useful. It was evident from this study, and an earlier study that collected Salmonella samples (Hammer et al., 2006), that these instruments must be decentralized to allow assignment of the result to a specified area of the environment, and that they may pose as a reservoir by themselves. To overcome the latter issue, after each positive finding, the cleaner has to be sanitized well. This procedure is very sophisticated, time consuming, and expensive, and therefore, not suitable for routine practice.

Over more than 10,000 end-product samples were analyzed for the presence of Enterobacteriaceae by the company-owned laboratory. This took place within the framework of the quality control system where, one line at a time (drying towers or roller dryers), the final product was screened for Enterobacteriaceae, using violet red bile dextrose (VRBD) agar (Merck KGaA, Darmstadt, Germany) at regular intervals at least 5 times a day. These samples are called microbiological trend analysis (MTA) samples. Violet red bile dextrose plates showing growth of presumptive Enterobacteriaceae were sent to our laboratory for further analysis. Of 


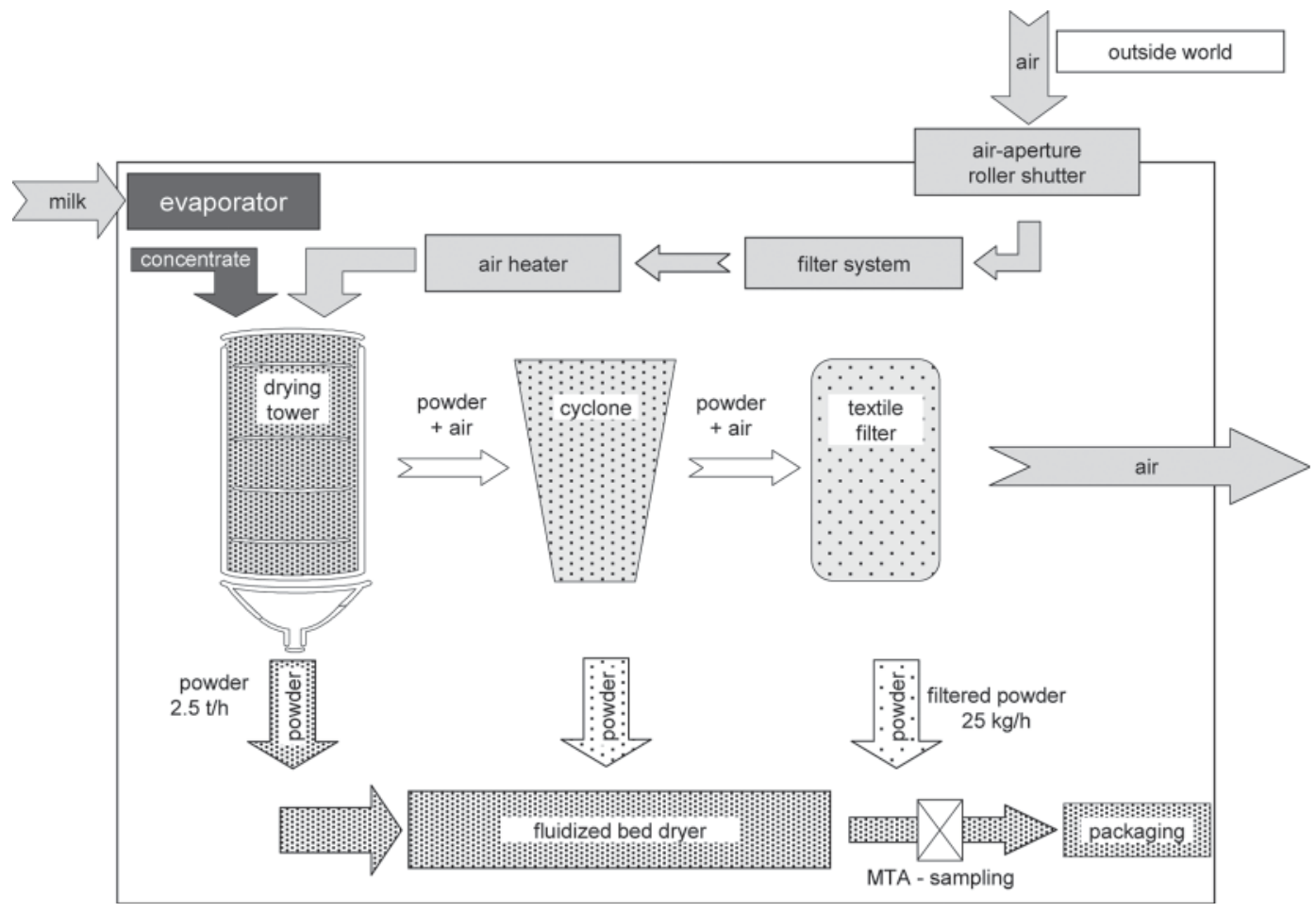

Figure 1. Flow diagram of the spray-drying process, the ventilation, and the drying air stream of the plant.

the 813 plates, 58 came from spraying tower I, 181 from tower II, and 574 from the roller dryers. Additionally, 124 samples of powder from the filters of the spraydrying towers (tower I: 58, tower II: 66), and 1,269 samples from the environment were examined in our laboratory. The latter were drawn by swabbing from defined areas along the process. From the spray-drying area, 1,149 samples were drawn; 120 were drawn from the roller-dryer area.

In the second period of investigations (2008-2009), 130 MTA plates from the roller-dryer area were analyzed. Additionally, from each dryer, a pair of samples was drawn. One sample was obtained from the concentrate (wet) side of the dryer and one from the dry side; the samples were drawn at the same time. Forty-two pairs were analyzed from each dryer (336 samples in total, 84 per dryer).

\section{Isolation of E. sakazakii}

For the isolation of E. sakazakii from the environmental samples, swabs were washed in $100 \mathrm{~mL}$ of double buffered peptone water [DPW; $20.0 \mathrm{~g} / \mathrm{L}$ (wt/vol) of peptone water (Oxoid GmbH, Wesel, Germany), 3.5 $\mathrm{g} / \mathrm{L}$ (wt/vol) of $\mathrm{Na}_{2} \mathrm{HPO}_{4}$ (Merck), and $1.5 \mathrm{~g} / \mathrm{L}$ (wt/ vol) of $\mathrm{KH}_{2} \mathrm{PO}_{4}$, (Merck)] by stomaching for 3 min at $260 \mathrm{rpm}$, and then incubated for 18 to $24 \mathrm{~h}$ at $37^{\circ} \mathrm{C}$.
For further enrichment, $10 \mathrm{~mL}$ of lauryl sulfate tryptose broth (LST; Merck) was inoculated with $0.1 \mathrm{~mL}$ of the pre-enrichment, and incubated at $45^{\circ} \mathrm{C}$ for 18 to $24 \mathrm{~h}$. Tryptone soy agar (TSA; Oxoid) was then inoculated with the LST culture with a loop and incubated at daylight for 24 to $48 \mathrm{~h}$ at room temperature. Yellow-pigmented colonies, one colony per plate, were then inoculated onto TSA supplemented with 4-methylumbelliferyl- $\alpha$-D-glucuronide $[15 \mathrm{mg} / \mathrm{L}$ (wt/ vol); Biosynth AG, Staad SG, Switzerland] and incubated for 18 to $24 \mathrm{~h}$ at $37^{\circ} \mathrm{C}$. Plates were evaluated under UV light $(366 \mathrm{~nm})$. Positively fluorescent colonies were further identified by API 20E (bioMérieux, Nürtingen, Germany) and were analyzed by PCR according to Lehner et al. (2004).

Treatment of the MTA-samples in the companyowned laboratory was as follows: $10 \mathrm{~g}$ of milk powder was diluted in DPW 1:10 (wt/vol), incubated for 18 to $24 \mathrm{~h}$ at $37^{\circ} \mathrm{C}$, and afterward, streaked onto VRBD. Enterobacteriaceae-positive plates were sent to our laboratory. Here, typical colonies were streaked again onto VRBD (Merck) and blood agar plates [Columbia agar supplemented with $5 \%$ (vol/vol) sheep blood; both Oxoid] and incubated for 18 to $24 \mathrm{~h}$ at $37^{\circ} \mathrm{C}$. Typical colonies (e.g., showing a yellow-pigmented center on both media) were streaked onto TSA and further processed as described above. 
For isolation of E. sakazakii from the powder derived from the filter, a quantitative approach was chosen. Amounts of $0.1,1$, and $10 \mathrm{~g}$ were dissolved 1:10 (wt/ vol) in DPW and incubated for 18 to $24 \mathrm{~h}$ at $37^{\circ} \mathrm{C}$. Of this pre-enrichment, $0.1 \mathrm{~mL}$ was inoculated into $10 \mathrm{~mL}$ of LST and treated further, similarly to the samples from the environment.

All E. sakazakii strains were stored at $-80^{\circ} \mathrm{C}$ in tryptone soya broth (Oxoid) supplemented with $10 \%$ vol/ vol glycerol (Merck).

\section{Pulsed-Field Gel Electrophoresis}

In situ DNA isolation was performed as described in Autio et al. (2002), with a few modifications. Isolates were streaked onto blood agar plates and incubated for 18 to $24 \mathrm{~h}$ at $37^{\circ} \mathrm{C}$. Medium-sized colonies were subsequently inoculated into $10 \mathrm{~mL}$ of brain heart infusion broth (Oxoid) and incubated for 18 to $24 \mathrm{~h}$ at $37^{\circ} \mathrm{C}$. Of this broth, $2 \mathrm{~mL}$ was transferred to a safe-lock cup, centrifuged at $15,000 \times g$, and the bacterial pellet was washed 3 times with TE buffer $[1 \mathrm{~m} M$ EDTA and 10 $\mathrm{m} M$ Tris- $\mathrm{HCl}$ (Merck), $\mathrm{pH}$ 8.0] and centrifuged for 15 $\min$ at $14,000 \times g$ at $4^{\circ} \mathrm{C}$. Inserts were produced by mixing the pellet in an equal volume of $0.8 \%$ agarose (InCert Agarose; BioWhittaker Molecular Applications, Rockland, ME) and subsequently distributed into 100- $\mu \mathrm{L}$ molds (plug mold; Bio-Rad Laboratories $\mathrm{GmbH}$, Munich, Germany). The plugs were lysed in lysis buffer for $3 \mathrm{~h}$ at $37^{\circ} \mathrm{C}$ [0.5\% Brij 58, $0.2 \%$ deoxycholate, $0.5 \%$ sodium lauroyl sarcosine, $1 \mathrm{mg}$ of lysozyme/ $\mathrm{mL}, 10 \mathrm{U}$ of mutanolysin/mL(Sigma-Aldrich Chemie $\mathrm{GmbH}$, Schnelldorf, Germany), $6 \mathrm{~m} M$ Tris-HCl ( $\mathrm{pH}$ 8.0), $100 \mathrm{~m} M$ EDTA (pH 8.0), $1 \mathrm{M} \mathrm{NaCl}$ (Merck), and $2.5 \mu \mathrm{g}$ of RNase/mL (Roche Diagnostics, Mannheim, Germany)]. After removal of the lysis buffer, the lysis continued for $1 \mathrm{~h}$ at $50{ }^{\circ} \mathrm{C}$ in ESP solution $[0.5 \mathrm{M}$ EDTA (pH 8.0; Merck), 10\% sodium lauroyl sarcosine, and $100 \mu \mathrm{g}$ of proteinase $\mathrm{K} / \mathrm{mL}$ (Sigma-Aldrich)], followed by a wash for $1 \mathrm{~h}$ at $50^{\circ} \mathrm{C}$ in $\mathrm{TE}$ buffer. The inactivation of proteinase $\mathrm{K}$ was achieved during the incubation of the plugs in TE buffer, supplemented with $1.2 \mathrm{~m} M$ Pefabloc SC (Merck), overnight at $37^{\circ} \mathrm{C}$. Prior to digestion, the plugs were washed 6 times for 30 min at $37^{\circ} \mathrm{C}$ in TE buffer. Equilibration for $30 \mathrm{~min}$ at room temperature and digestion overnight at $37^{\circ} \mathrm{C}$ was performed in $\mathrm{Y}^{+} /$TANGO buffer (Fermentas $\mathrm{GmbH}$, Sankt Leon-Rot, Germany; $33 \mathrm{~m} M$ Tris-acetate, $10 \mathrm{~m} M$ magnesium acetate, $66 \mathrm{mM}$ potassium acetate, and 0.1 $\mathrm{mg}$ of BSA $/ \mathrm{mL}$ ). Restriction endonucleases SpeI and $\mathrm{Xba \textrm {I }}$ (Fermentas $\mathrm{GmbH}$ ) were used at a concentration of $10 \mathrm{U} / 150 \mu \mathrm{L}$ each for the digestion of a plug of 2.5 $\times 5 \times 5 \mathrm{~mm}$.
Electrophoresis was performed in a $1 \%$ SeaKem agarose gel (SeaKem Agarose; Cambrex Bioscience Rockland Inc., Rockland, ME); the agarose was dissolved in $0.5 \times$ TBE-buffer (Tris-borate-EDTA-buffer; Sigma-Aldrich) supplemented with $100 \mu M$ thiourea (Merck). The same buffer was also used as running buffer. The electrophoresis chamber and all supplementary equipment was the Chef-DR III system (Bio-Rad Laboratories $\mathrm{GmbH}$ ). Running conditions were as follows: $22 \mathrm{~h}, 10^{\circ} \mathrm{C}$, angle $120^{\circ}, 6 \mathrm{~V}$; pulse time SpeI $4 / 40$ s; pulse time $X b a \mathrm{I} 5 / 50 \mathrm{~s}$. The gels were then stained in a bath of ethidium bromide in double-distilled water $[200 \mu \mathrm{L}$ of $1 \%$ ethidium bromide solution (Merck) in $400 \mathrm{~mL}$ of water, vol/vol] for $35 \mathrm{~min}$. For determination of fragment length, Pulse Marker 50-1,000 $\mathrm{kb}$ (Sigma-Aldrich) was used. The gels were digitally photographed in a UV-transilluminator (Gel Doc 2000; Bio-Rad Laboratories GmbH).

\section{PFGE Pattern Analysis}

Cluster analysis was performed with GelCompar II, version 5.10 (Applied Maths, Sint-Martens-Latem, Belgium) using the following settings for both restriction endonucleases: $1 \%$ optimization and $1.2 \%$ position tolerance. The similarity between band positions was determined by Dice similarity coefficient. For construction of dendrograms, the unweighted pair group method using arithmetic averages (UPGMA) algorithm was selected. The work from Tenover et al. (1995) was used as an aid for the interpretation of the banding patterns.

\section{RESULTS AND DISCUSSION}

\section{Investigations 2005 to 2007}

During the first period between 2005 and 2007, the company-owned laboratory tested more than 10,000 MTA samples (final-product samples). Eight hundred and thirteen VRBD plates showing growth of presumptive Enterobacteriaceae were sent to our laboratory for further analysis. Enterobacter sakazakii was isolated from 78 of 181 plates from spray-drying tower I, no $E$. sakazakii were isolated from the 58 plates from tower II and 60 were isolated from the 574 plates from the roller dryers. From each VRBD plate, only 1 presumptive colony was isolated. Examination of the powder from the filters yielded 48 isolates out of 58 samples from tower I, and 62 out of 66 samples from tower II. In total, 1,269 environmental samples were tested for the presence of E. sakazakii, resulting in 39 isolates from the area of tower I, 29 from tower II, and 39 from the roller dryer area (Table 1). Most of the isolates 
Table 1. Number of isolates of Enterobacter sakazakii from the spray-drying and roller-drying areas of a milk powder-producing facility (2005-2007)

\begin{tabular}{|c|c|c|c|c|c|c|}
\hline $\begin{array}{l}\text { Sample } \\
\text { origin }\end{array}$ & \multicolumn{2}{|c|}{ Drying tower I } & \multicolumn{2}{|c|}{ Drying tower II } & \multicolumn{2}{|c|}{ Roller dryers } \\
\hline Filter powder & 58 & 48 & 66 & 62 & $\mathrm{NA}^{2}$ & NA \\
\hline Environment & 551 & 39 & 598 & 29 & 120 & 39 \\
\hline
\end{tabular}

${ }^{1}$ Microbiological trend analysis (from final product).

${ }^{2}$ Not applicable.

were identified from the processing area, confirming the results of Proudy et al. (2008).

Selected isolates of E. sakazakii from MTA samples, isolates from the powder derived from the filter, and isolates from the environmental samples of the spraydrying area were subjected to PFGE analysis to gain an overview on the epidemiology of the contamination. These isolates could be assigned to 7 PFGE types (Figure 2). This diversity of PFGE types was most probably caused by continuous entry of E. sakazakii strains into the facility, due to openings in the barrier between the outside and the production area. Unfortunately, a $15-\mathrm{m}^{2}$ aperture was used for the aeration of the plant and a roller shutter was used for the exchange of goods without proper control, which led to a violation of the hygienic zoning concept. As can be seen from the dates of isolation displayed in Figure 2, some PFGE types persisted over years (no. 1, 2), some for a few months (no. 4, 5) and some turned up only 1 or 2 times (no. $3,6,7)$. The long persistence of types 1 and 2 was an indication that a reservoir for these must exist in the production area. Interestingly, MTA samples from drying tower II never showed contamination with $E$. sakazakii, though the powder obtained from the filter of both towers did. All isolates from the powder from the filter and MTA samples of tower I belonged to pulsotypes 1,2 , or 3 , whereas isolates from filter powder of tower II belonged predominantly to types 4 and 5 , with the exception of one isolate belonging to type 1 (Figure 2, lane 9). A separate PFGE evaluation of the isolates from tower I and its filter is shown in Figure 3. All isolates identified as pulsotype A belong either to pulsotype 1 or 2, as illustrated in Figure 2. Type A was present over a period of almost $3 \mathrm{yr}$. A common practice in the plant was to reintroduce filter powder into the main product flow for economic reasons ( $1 \%$ of the production is filter powder). However, this was applied for tower I only from time to time and never for tower II. This clearly identified the filter of tower I as a reservoir for E. sakazakii. Supporting this hypothesis was the finding that some of the tested isolates were true pairs, which means isolates from the MTA samples and filter powder that were obtained from the sites on the same day or in a close chronological sequence (Figure 3, lanes $1,7,9 ; 2,10 ; 3,4 ; 5,11)$. By communicating with the plant staff and referring to the production records of the plant, it could also be concluded that MTA samples only yielded isolates of E. sakazakii if the filter powder was reintroduced into the final product. This showed that the drying process as such was safe with regard to a contamination with E. sakazakii and that the source for recontamination was the filter powder. Further, it can be assumed that the environmental contamination with pulsotypes 1 and 2 (Figure 2) detected in the spray-drying area also originated from the filter of tower I. The filters were opened for a mechanical cleaning at regular intervals, leading to the contamination of the environment with the contaminated milk powder. These findings are in agreement with the Mullane et al. (2008) study, where air filters were also identified as entry route of E. sakazakii.

Recently, an identical problem has been detected in another milk powder-producing plant, which uses a very similar filter system and also reintroduces the filter powder into the final product (data not shown).

During our investigation, it was not possible to identify how the filters were contaminated. One possibility is through exposure to the environment during the mechanical cleaning process. It also can be speculated that E. sakazakii is able to survive the spray-drying process. This has been described in Arku et al. (2008), where a 6.1 to $7.6 \log$ reduction of bacteria at $160^{\circ} \mathrm{C}$ was reported; however, bacterial survivors were still detected. The factory in the current study uses $210^{\circ} \mathrm{C}$ as the drying temperature, which is much higher than used by the factory in the Arku et al. (2008) study. However, it is known that Salmonella can survive at $210^{\circ} \mathrm{C}$ (LiCari and Potter, 1970; Miller et al., 1972). As soon as bacteria are present in the filters, growth is possible. Textile filter hoses (used in the factory in this study) tend to collect condensing water during standstill times. The powdered milk that is present also aids in the growth of the bacteria because the powdered milk is hygroscopic and offers nutrients to the contami- 
JACOBS ET AL.

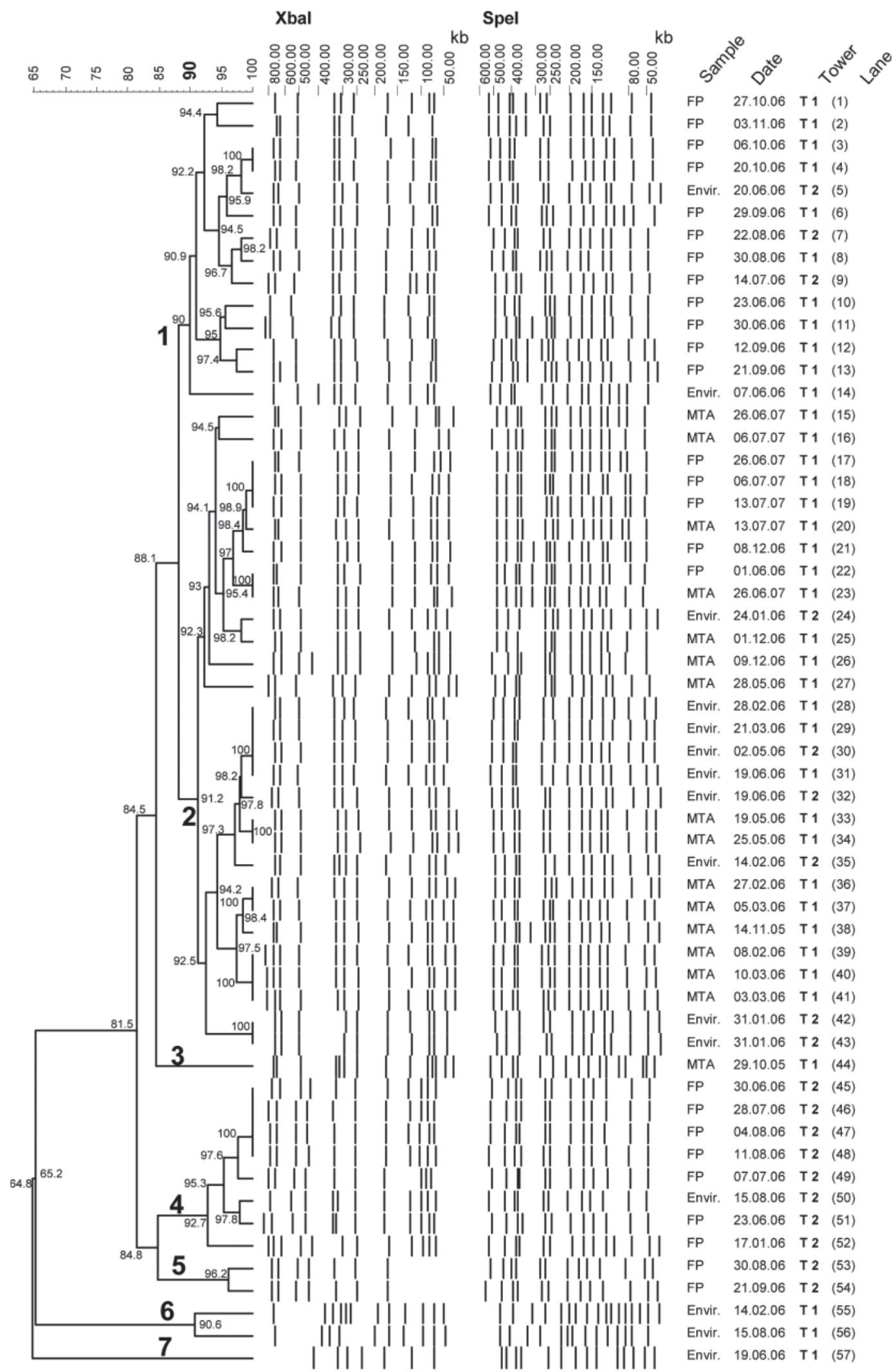

Figure 2. Pulsed-field gel electrophoresis (PFGE) typing of Enterobacter sakazakii isolates from both of the drying towers, the respective filters, and the environment of the spray-drying process. FP $=$ filter powder; MTA = microbiological trend analysis (final product); Envir. $=$ environment. Date of isolation is given as dd.mm.yy and pulsotypes are numbered 1 to 7 . XbaI and SpeI are restriction endonucleases. 


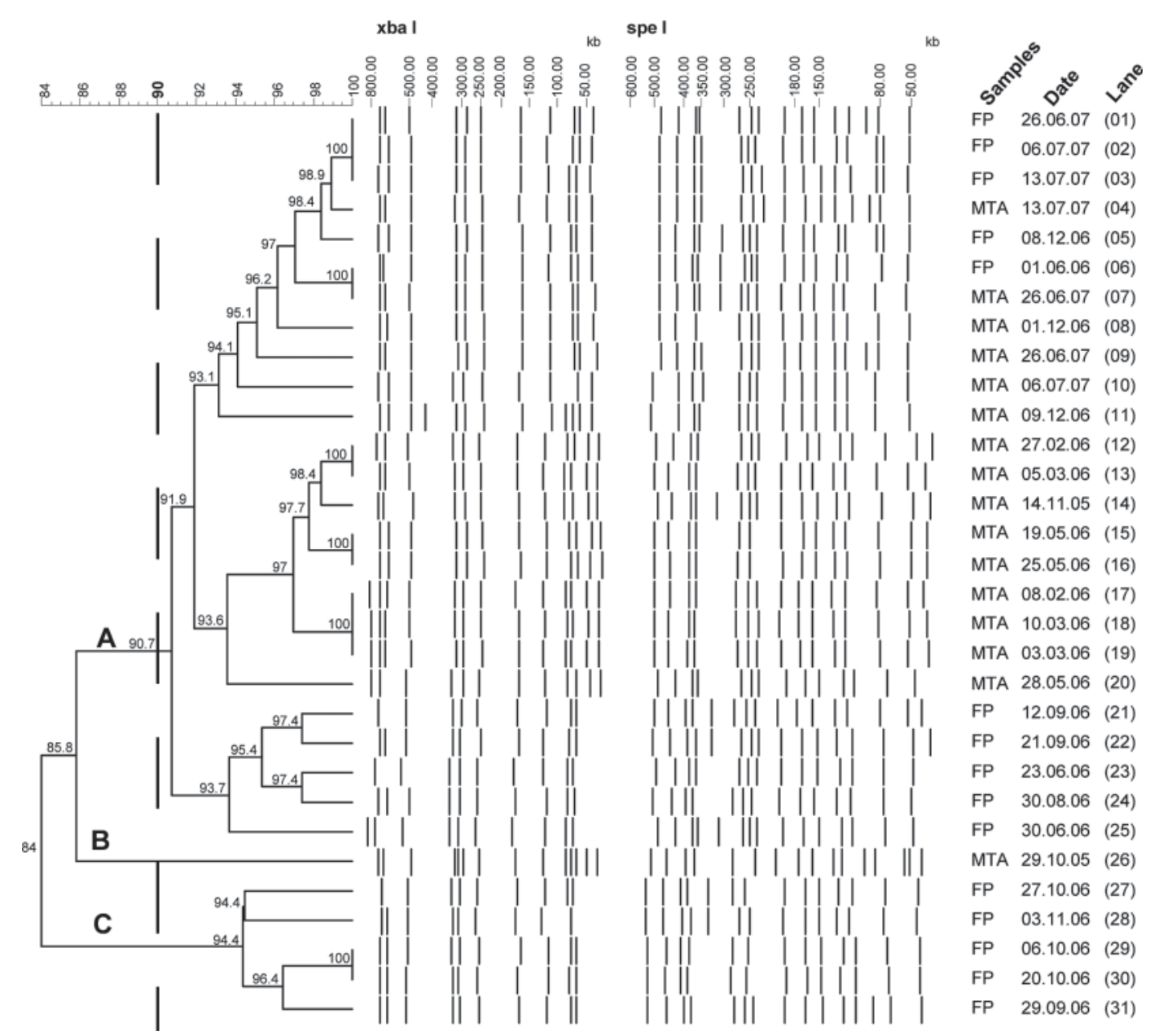

Figure 3. Pulsed-field gel electrophoresis (PFGE) typing of selected Enterobacter sakazakii isolates of the first spray-drying tower. FP = filter powder; MTA = microbiological trend analysis (final product). Dotted vertical line: discriminator for clonal identity set at $90 \%$ according to Tenover et al. (1995). Date of isolation is given as dd.mm.yy and pulsotypes are named A, B, C. XbaI and SpeI are restriction endonucleases.

nating bacteria. Standstill times in this factory are between a few days and up to several weeks, resulting in a temperature decrease in the production area to ambient temperature. Even during production, temperatures in the filters do not exceed $60^{\circ} \mathrm{C}$. Occurrence of microbial growth is regularly registered by the factory-owned laboratory when monitoring the filter powder for yeasts and molds.

Decontamination, or an annual exchange of the textile filters, is insufficient for a significant improvement in quality of the filter powder. Therefore, we recommend that this factory should (a) exchange the textile filters by a clean-in-place (CIP) suitable system or (b) discontinue the reintroduction of the filtered powder to the product flow if it wishes to produce powdered milk to be supplied in infant formula. However, this factory is not presently producing any products that go into infant formula.
Isolates of E. sakazakii from the roller-dryer area were different from those from the spray-drying area (data not shown). This could be expected, as the buildings were different and respective double door locks properly managed personnel traffic. In total, 9 different pulsotypes were isolated from MTA samples and from environmental samples of the roller-drying area (data not shown). The high number of positive MTA samples from the roller dryers may be an indication of poor hygiene. In fact, the whole roller-dryer area is a wet area. The dryers are open systems leading to contamination of the floor; splashes and droplets of milk concentrate have to be rinsed off the floors during production for the safety of personnel. Though this is performed with caution, formation of aerosols and subsequent contamination of the dried product cannot be fully avoided. In addition, a roller shutter was used here without proper control. 


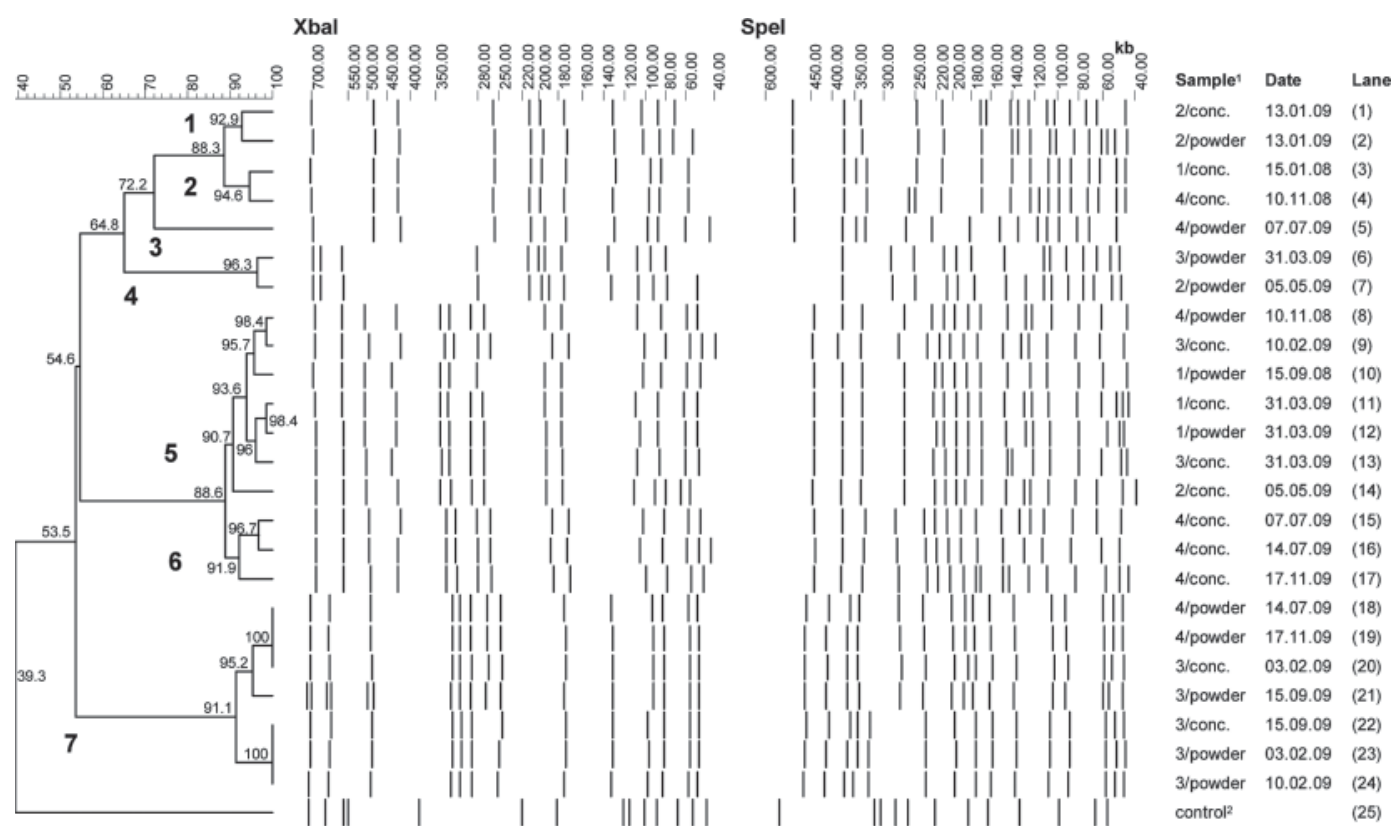

Figure 4. Pulsed-field gel electrophoresis (PFGE) typing of selected Enterobacter sakazakii isolates from the roller dryers. Date of isolation is given as dd.mm.yy and pulsotypes are numbered 1 to 7 . Samples are identified as dryer number/sample type (conc. = concentrate); the control strain was E. sakazakii DSMZ 4485. XbaI and SpeI are restriction endonucleases.

\section{Investigations 2008 to 2009}

In the second period of the project, we investigated whether E. sakazakii can be transmitted within the roller-drying process. This was suggested due to one downside of using the roller dryers. Milk concentrate was continuously fed into a square trough, from where a system of rollers applied a thin film of concentrate to the heated drying roll. The temperature of the concentrate during the feeding was about $60^{\circ} \mathrm{C}$. However, it could decrease to below $45^{\circ} \mathrm{C}$ in the corners of the trough because of improper circulation. Because production time was more than $20 \mathrm{~h}$, considerable bacterial growth could be expected. During several inspections, it was noted that splashes or droplets of concentrate from the edges of the drying rolls occasionally could pass to the dry side of the system by passing through a gap between the drying roll and the frame where the axis of the roll was pivoted. Over a period of 1 yr, pairs of samples from the wet and the dry side of each roller dryer were collected: 366 samples in total. Enterobacter sakazakii was isolated from 56 samples of the concentrate and 44 samples of the powder, equally distributed between the 4 dryers. Of these, 12 pairs of strains, isolated on the same day from both sides of a dryer were subjected to PFGE. This led to the identification of 7 pulsotypes (Figure 4). Detection of the same pulsotypes in 3 different pairs (lanes 1, 2; $11,12 ; 21,22)$ was indicative of direct transmission.
However, reciprocal contamination from the environment cannot be excluded. For example, looking at the isolation from Nov. 17, 2009 (lanes 17, 19), pulsotypes isolated from the concentrate and the powder from the same dryer were quite different. But on March 3, 2009, a true pair was isolated from dryer 1 and from powder derived from dryer 3 (lanes 11-13). The PFGE typing showed that direct, crosswise, and reciprocal contaminations of the final product with E. sakazakii were all possible. This was most likely due to the high possibility of contamination coming from the environment, which was detected in the first period of this study. We can exclude the possibility that contamination was derived from improperly cleaned production facilities by respective sampling (data not shown).

\section{CONCLUSIONS}

This study demonstrated that textile filters for exhaust air can be a reservoir for E. sakazakii during milk powder production; thus, they pose a risk for contamination of the environment and of the final product if the filter powder is reintroduced into the product flow. If this reintroduction technique is used for producing ingredients for infant formula, it should be halted if contamination is found. Additionally, the facility should investigate whether such contamination already exists. Production of roller-dryer powder seemed to be the most problematic process. Contamination of the 
final product from this source was frequent. This contaminated powder should not be used to produce infant formula unless it is reconstituted and subsequently heat treated. It should be noted that milk powder is not a sterile product; this must be considered in the production of infant formula. This should also be communicated to the people in charge of handling and preparing powdered infant formula. This warning has already been published by several institutions such as the FDA (2002), the Food and Agriculture Organization of the United Nations and the World Health Organization (FAO/WHO, 2004), and the European Food Safety Authority (EFSA, 2007).

\section{ACKNOWLEDGMENTS}

The thank the staff of the Max Rubner-Institute (Kiel, Germany), Beate Bonniksen, Kirstin Franzen, Ilona Huldberg, and Maren Schmidt, for excellent technical assistance. We are also very grateful for financial support from the company that owns the milk powderproducing plant, which must remain anonymous. In addition, we thank the staff of the plant, which also must remain anonymous, for open-minded cooperation and the supply of samples.

\section{REFERENCES}

Arku, B., N. Mullane, E. Fox, S. Fanning, and K. Jordan. 2008. Enterobacter sakazakii survives spray drying. Int. J. Dairy Technol. 61:102-108.

Arseni, A., E. Malamou-Ladas, C. Koutsia, M. Xanthou, and E. Trikka. 1987. Outbreak of colonization of neonates with Enterobacter sakazakii. J. Hosp. Infect. 9:143-150.

Autio, T., J. Lundén, M. Fredriksson-Ahomaa, J. Björkroth, A.-M. Sjöberg, and H. Korkeala. 2002. Similar Listeria monocytogenes pulsotypes detected in several foods originating from different sources. Int. J. Food Microbiol. 77:83-90.

Biering, G., S. Karlsson, N. C. Clark, K. E. Jónsdóttir, P. Lúdvígsson, and O. Steingrímsson. 1989. Three cases of neonatal meningitis caused by Enterobacter sakazakii in powdered milk. J. Clin. Microbiol. 27:2054-2056.

Block, C., O. Peleg, N. Minster, B. Bar-Oz, A. Simhon, I. Arad, and M. Shapiro. 2002. Cluster of neonatal infections in Jerusalem due to biochemical variant of Enterobacter sakazakii. Eur. J. Clin. Microbiol. Infect. Dis. 21:613-616.

Coignard, B., V. Vaillant, J.-P. Vincent, A. Leflèche, P. MarianiKurkdjian, C. Bernet, F. L’Hériteau, H. Sénéchal, P. Grimont, E. Bingen, and J.-C. Desenclos. 2006. Infections sévères à Enterobacter sakazakii chez des nouveau-nés ayant consommé und préparation en poudre pour nourrissons, France, Octobre-Décembre 2004. Bulletin Épidémiologique Hebdomadaire 2-3:10-13.

Craven, H. M., C. M. McAuley, L. L. Duffy, and N. Fegan. 2010. Distribution, prevalence and persistence of Cronobacter (Enterobacter sakazakii) in the nonprocessing and processing environments of five milk powder factories. J. Appl. Microbiol. 109:1044-1052. doi:10.1111/j.1365-2672.2010.04733.x.

Drudy, D., N. R. Mullane, T. Quinn, P. G. Wall, and S. Fanning. 2006. Enterobacter sakazakii: An emerging pathogen in powdered infant formula. Clin. Infect. Dis. 42:996-1002.
EFSA (European Food Safety Authority). 2007. Scientific opinion of BIOHAZ Panel on the request from the Commission for review of the opinion on microbiological risks in infant formulae and followon formulae with regard to Enterobacteriaceae as indicators. Report No. EFSA-Q-2006-078. EFSA J. 444:1-14.

FAO/WHO. 2004:Enterobacter sakazakii and other micro-organisms in powdered infant formula. Meeting report. Microbiological Risk Assessment Series 6. The Food and Agriculture Organization of the United Nations and the World Health Organization. Accessed Feb. 28, 2011. http://www.fao.org/ag/agn/agns/jemra_riskassessment_enterobacter_en.asp.

FDA. 2002. Health professionals letter on Enterobacter sakazakii infections associated with use of powdered (dry) infant formulas in neonatal intensive care units. US Food and Drug Administration, Center for Food safety and Applied Nutrition, Office of Nutritional Products, Labeling and Dietary Supplements. Accessed Feb. 28, 2011. http://www.fda.gov/Food/FoodSafety/Product-Specific Information/InfantFormula/AlertsSafetyInformation/ucm111299. htm.

Grimont, F., and P. A. Grimont. 2006. The Genus Enterobacter. Pages 197-214 in The Prokaryotes. M. Dworkin, S. Falkow, E. Rosenberg, K.-H. Schleifer, and E. Stackebrandt, ed. Springer-Verlag, New York, NY.

Hamilton, J. V., M. J. Lehane, and H. R. Braig. 2003. Isolation of Enterobacter sakazakii from midgut of Stomoxys calcitrans. Emerg. Infect. Dis. 9:1355-1356.

Hammer, P., K. Knappstein, and P. Teufel. 2006. Umfeld- versus Endproduktmonitoring-Praktische Erfahrungen bei der Kontrolle von Salmonella-Kontaminationen im Umfeld einer Milchtrocknungsanlage. Kieler Milchwirtschaftliche Forschungsberichte 58:59-80.

Hawkins, R. E., C. R. Lissner, and J. P. Sanford. 1991. Enterobacter sakazakii bacteremia in an adult. South. Med. J. 84:793-795.

Hein, I., B. Gadzov, D. Schoder, H. Foissy, B. Malorny, and M. Wagner. 2009. Temporal and spatial distribution of Cronobacter isolates in a milk powder processing plant determined by pulsed-field gel electrophoresis. Foodborne Pathog. Dis. 6:225-233.

Himelright, I., E. Harris, V. Lorch, M. Anderson, M. Kuehnert, T. Forster, M. Arduino, B. Jensen, and D. Jernigan. 2002. Enterobacter sakazakii infections associated with the use of powdered infant formula-Tennessee, 2001. CDC Morbidity and Mortality Weekly Report 51:297-300.

Iversen, C., N. Mullane, B. McCardell, B. D. Tall, A. Lehner, S. Fanning, R. Stephan, and H. Joosten. 2008. Cronobacter gen. nov., a new genus to accommodate the biogroups of Enterobacter sakazakii, and proposal of Cronobacter sakazakii gen. nov., comb. nov., Cronobacter malonaticus sp. nov., Cronobacter turicensis sp. nov., Cronobacter muytjensii sp. nov., Cronobacter dublinensis sp. nov., Cronobacter genomospecies 1, and of three subspecies, Cronobacter dublinensis subsp. dublinensis subsp. nov., Cronobacter dublinensis subsp. lausannensis subsp. nov. and Cronobacter dublinensis subsp. lactaridi subsp. nov. Int. J. Syst. Evol. Microbiol. 58:1442-1447.

Kandhai, M. C., M. W. Reij, L. G. M. Gorris, O. Guillaume-Gentil, and M. van Schothorst. 2004. Occurrence of Enterobacter sakazakii in food production environments and households. Lancet 363:39-40.

Kim, H., and L. R. Beuchat. 2005. Survival and growth of Enterobacter sakazakii on fresh-cut fruits and vegetables and in unpasteurized juices as affected by storage temperature. J. Food Prot. 68:2541-2552.

Lai, K. K. 2001. Enterobacter sakazakii infections among neonates, infants, children, and adults. Case reports and a review of the literature. Medicine (Baltimore) 80:113-122.

Leclercq, A., C. Wanegue, and P. Baylac. 2002. Comparison of fecal coliform agar and violet red bile lactose agar for fecal coliform enumeration in foods. Appl. Environ. Microbiol. 68:1631-1638.

Lehner, A., and R. Stephan. 2004. Microbiological, epidemiological, and food safety aspects of Enterobacter sakazakii. J. Food Prot. 67:2850-2857. 
Lehner, A., T. Tasara, and R. Stephan. 2004. 16 S rRNA gene based analysis of Enterobacter sakazakii strain from different sources and development of a PCR assay for identification. BMC Microbiol. $4: 43$.

LiCari, J. J., and N. N. Potter. 1970. Salmonella survival during spray drying and subsequent handling of skimmilk powder. I. Salmonella enumeration. J. Dairy Sci. 53:865-870.

Miller, D. L., J. M. Goepfert, and C. Amundson. 1972. Survival of Salmonellae and Escherichia coli during the spray drying of various food products. J. Food Sci. 37:828-831.

Mosso, M. A., M. D. C. Da La Rosa, C. Vivar, and M. D. R. Medina 1994. Heterotrophic bacterial populations in the mineral waters of thermal springs in Spain. J. Appl. Bacteriol. 77:370-381.

Mullane, N., B. Healy, J. Meade, P. Whyte, P. G. Wall, and S. Fanning. 2008. Dissemination of Cronobacter spp. (Enterobacter sakazakii) in a powdered milk protein manufacturing facility. Appl. Environ. Microbiol. 74:5913-5917.

Mullane, N. R., P. Whyte, P. G. Wall, T. Quinn, and S. Fanning. 2007 Application of pulsed-field gel electrophoresis to characterise and trace the prevalence of Enterobacter sakazakii in an infant formula processing facility. Int. J. Food Microbiol. 116:73-81.

Muytjens, H. L., and L. A. Kollée. 1990. Enterobacter sakazakii meningitis in neonates: Causative role of formula? Pediatr. Infect. Dis. J. $9: 372-373$.

Muytjens, H. L., H. C. Zanen, H. J. Sonderkamp, L. A. Kollée, I. K. Wachsmuth, and J. J. Farmer 3rd. 1983. Analysis of eight cases of neonatal meningitis and sepsis due to Enterobacter sakazakii. J. Clin. Microbiol. 18:115-120.
Nazarowec-White, M., and J. M. Farber. 1999. Phenotypic and genotypic typing of food and clinical isolates of Enterobacter sakazakii. J. Med. Microbiol. 48:559-567.

Nazarowec-White, M., J. M. Farber, M. W. Reij, J. L. Cordier, and M. Van Schothorst. 2003. Enterobacter sakazakii. Pages 407-413 in International Handbook of Foodborne Pathogens. M. D. Miliotis and J. W. Bier, ed. Marcel Dekker Inc., New York, NY.

Proudy, I., D. Bouglé, R. Leclercq, and M. Vergnaud. 2008. Tracing of Enterobacter sakazakii isolates in infant milk formula processing by BOX-PCR genotyping. J. Appl. Microbiol. 105:550-558.

Reich, F., R. König, W. von Wiese, and G. Klein. 2010. Prevalence of Cronobacter spp. in a powdered infant formula processing environment. Int. J. Food Microbiol. 140:214-217.

Stoll, B. J., N. Hansen, A. A. Fanaroff, and J. A. Lemons. 2004. Enterobacter sakazakii is a rare cause of neonatal septicemia or meningitis in vlbw infants. J. Pediatr. 144:821-823.

Tenover, F. C., R. D. Arbeit, R. V. Goering, P. A. Mickelsen, B. E. Murray, D. H. Persing, and B. Swaminathan. 1995. Interpreting chromosomal DNA restriction patterns produced by pulsed-field gel electrophoresis: Criteria for bacterial strain typing. J. Clin. Microbiol. 33:2233-2239.

van Acker, J., F. de Smet, G. Muyldermans, A. Bougatef, A. Naessens, and S. Lauwers. 2001. Outbreak of necrotizing enterocolitis associated with Enterobacter sakazakii in powdered milk formula. J. Clin. Microbiol. 39:293-297.

Willis, J., and J. E. Robinson. 1988. Enterobacter sakazakii meningitis in neonates. Pediatr. Infect. Dis. J. 7:196-199. 